Article

\title{
Neuromuscular Activity of Micrurus laticollaris (Squamata: Elapidae) Venom in Vitro
}

\author{
Alejandro Carbajal-Saucedo ${ }^{1}$, Rafael Stuani Floriano ${ }^{2}$, Cháriston André Dal Belo ${ }^{3}$, \\ Alejandro Olvera-Rodríguez ${ }^{1}$, Alejandro Alagón ${ }^{1}$ and Léa Rodrigues-Simioni ${ }^{2, *}$
}

1 Instituto de Biotecnología, Universidad Nacional Autónoma de México, Av. Universidad 2001, Col. Chamilpa, Cuernavaca, Morelos, CP. 62210, Mexico;

E-Mails: micropechis@yahoo.com.mx (A.C.-S.); aolvera@ibt.unam.mx (A.O.-R.); alagon@ibt.unam.mx (A.A.)

2 Department of Pharmacology, Faculty of Medical Sciences, State University of Campinas (UNICAMP), Tessália Vieira Camargo St., 126, Campinas, SP 13083-887, Brazil; E-Mail: floriano_rs@yahoo.com

3 Interdisciplinar Center for Biotechnology (CIPBiotec), Campus São Gabriel, Federal University of Pampa (UNIPAMPA), Antônio Trilha Av., 1847, São Gabriel, RS 97300-000, Brazil; E-Mail: charistondb@gmail.com

* Author to whom correspondence should be addressed; E-Mail: simioni@unicamp.br; Tel.: +55-193-521-9533; Fax: +55-193-289-5846.

Received: 25 October 2013; in revised form: 20 December 2013 / Accepted: 30 December 2013 / Published: 17 January 2014

\begin{abstract}
In this work, we have examined the neuromuscular activity of Micrurus laticollaris (Mexican coral snake) venom (MLV) in vertebrate isolated nerve-muscle preparations. In chick biventer cervicis preparations, the MLV induced an irreversible concentration- and time-dependent (1-30 $\mu \mathrm{g} / \mathrm{mL})$ neuromuscular blockade, with $50 \%$ blockade occurring between 8 and $30 \mathrm{~min}$. Muscle contractures evoked by exogenous acetylcholine were completely abolished by MLV, whereas those of $\mathrm{KCl}$ were also significantly altered $(86 \% \pm 11 \%, 53 \% \pm 11 \%, 89 \% \pm 5 \%$ and $89 \% \pm 7 \%$ for one, three, 10 and $30 \mu \mathrm{g}$ of venom $/ \mathrm{mL}$, respectively; $n=4 ; p<0.05)$. In mouse phrenic nerve-diaphragm preparations, MLV $(1-10 \mu \mathrm{g} / \mathrm{mL})$ promoted a slight increase in the amplitude of twitch-tension $(3 \mu \mathrm{g} / \mathrm{mL})$, followed by neuromuscular blockade $(n=4)$; the highest concentration caused complete inhibition of the twitches (time for $50 \%$ blockade $=26 \pm 3 \mathrm{~min}$ ), without exhibiting a previous neuromuscular facilitation. The venom $(3 \mu \mathrm{g} / \mathrm{mL})$ induced a biphasic modulation in the frequency of
\end{abstract}


miniature end-plate potentials (MEPPs)/min, causing a significant increase after $15 \mathrm{~min}$, followed by a decrease after $60 \mathrm{~min}$ (from $17 \pm 1.4$ (basal) to $28 \pm 2.5\left(t_{15}\right)$ and $\left.12 \pm 2\left(t_{60}\right)\right)$. The membrane resting potential of mouse diaphragm preparations pre-exposed or not to d-tubocurarine $(5 \mu \mathrm{g} / \mathrm{mL})$ was also significantly less negative with MLV $(10 \mu \mathrm{g} / \mathrm{mL})$. Together, these results indicate that $M$. laticollaris venom induces neuromuscular blockade by a combination of pre- and post-synaptic activities.

Keywords: snake venom; Micrurus laticollaris; presynaptic action; postsynaptic action; neuromuscular preparations

\section{Introduction}

Coral snakes (formally included in the genera, Micrurus, Leptomicrurus and Micruroides) constitute a taxonomic assemblage of more than 120 species and subspecies [1-3] distributed from the southern United States to southern South America, achieving their greatest abundance of species in lower latitudes [4], and they are, together with the pelagic sea snake, Pelamis platurus, the American representatives of the family, Elapidae [5,6]. Their venoms contain low-molecular mass neurotoxins of the three-finger type, which block the neuromuscular junction by binding with high affinity to the cholinergic receptor at the neuromuscular junction, promoting a paralytic effect [7-10]. In addition, Micrurus venoms contain phospholipase $\mathrm{A}_{2}$, which can induce myotoxicity [11-14], hemorrhage [15], inflammation [16] and presynaptic neurotoxicity [17,18].

Micrurus laticollaris is one of the most important snakes of medical importance in Mexico [19]. Recently, a short-chain alpha-neurotoxin has been isolated from M. laticollaris venom, which appears to be determinant in the whole envenomation [20]. However, data related to the interaction of M. laticollaris crude venom at the neuromuscular junction are scarce and become a valuable source of information to improve the clinical treatment of snakebite accidents. In addition, in spite of its obvious clinical interest, the study of the whole venom uncovers the presence of other toxins that are no less important in terms of potential medical applications. In this work, we investigated the neuromuscular activity of the crude venom from the Mexican coral snake, M. laticollaris.

\section{Results and Discussion}

Micrurus laticollaris venom (1-30 $\mathrm{g} / \mathrm{mL})$ caused irreversible time- and concentration-dependent neuromuscular blockade in indirectly stimulated biventer cervicis (BC) preparations, with complete blockade occurring from $20 \mathrm{~min}$ at the highest concentration $(30 \mu \mathrm{g} / \mathrm{mL})$ (Figure 1A). The times required for $50 \%$ blockade were $36 \pm 4.6,11 \pm 0.9$ and $8 \pm 0.6 \mathrm{~min}$ for three, 10 and $30 \mu \mathrm{g} \mathrm{venom} / \mathrm{mL}$, respectively. All tested venom concentrations completely inhibited the contractures to exogenous ACh $(110 \mu \mathrm{M})$ after neuromuscular blockade, whereas contractures to $\mathrm{KCl}(40 \mathrm{mM})$ had a minor change $(86 \pm 11,53 \pm 11,89 \pm 5$ and $89 \pm 7$ for $1,3,10$ and $30 \mu \mathrm{g}$ of venom $/ \mathrm{mL}$, respectively, expressed as a percentage of the control, considered as 100\%; $n=4$ each) (Figure 1B). Figure 3A shows a representative record of the neuromuscular blockade caused by a venom concentration of $10 \mu \mathrm{g} / \mathrm{mL}$ 
and contracture responses to $\mathrm{ACh}$ and $\mathrm{KCl}$ before and after venom treatment. The decrease of the twitch tension in avian neuromuscular preparations caused by Elapidic venoms has been previously shown [13,21-25]. At these preparations, the muscle-type nicotinic receptors are distributed alongside the muscle fiber characterizing the multiple neuromuscular junctions [26]. Frequently, in multi-innervated nerve-muscle preparations treated with Elapidic venoms, the decrease of the amplitude of muscle twitches is accompanied by the attenuation or complete blockade of the muscle contracture induced by exogenous ACh. In these preparations, the inhibition of both twitch-tension and muscle contracture response to exogenous ACh caused by Elapidic venoms is known to be due the presence of alpha-neurotoxins [27-29]. These toxins act specifically on neuronal and muscle-type nicotinic receptors, preventing the binding of Ach, which inhibits the sodium influx and, consequently, the membrane depolarization [20,28]. Indeed, a novel short-chain alpha neurotoxin was identified from Micrurus laticollaris venom, which is able to inhibit the biding of ACh at cloned nicotinic receptors expressed at Xenopus laevae [20].

Figure 1. Neuromuscular blockade caused by M. laticollaris venom (one, three, 10 and $30 \mu \mathrm{g} / \mathrm{mL}$ ) in biventer cervicis (BC) preparations. (A) Graphic of the concentration- and time-dependent blockade; (B) Columns representing muscle contractures to exogenous ACh $(110 \mu \mathrm{M})$ and $\mathrm{KCl}(40 \mathrm{mM})$ after $120 \mathrm{~min}$ of incubation or complete neuromuscular blockade are expressed as a percentage of the responses observed in control preparations (Krebs solution alone). The points in $\mathbf{A}$ and the columns in $\mathbf{B}$ are the mean $\pm \operatorname{SEM}(n=4)$; $* p<0.05$ compared to control preparations in both A and B panels.
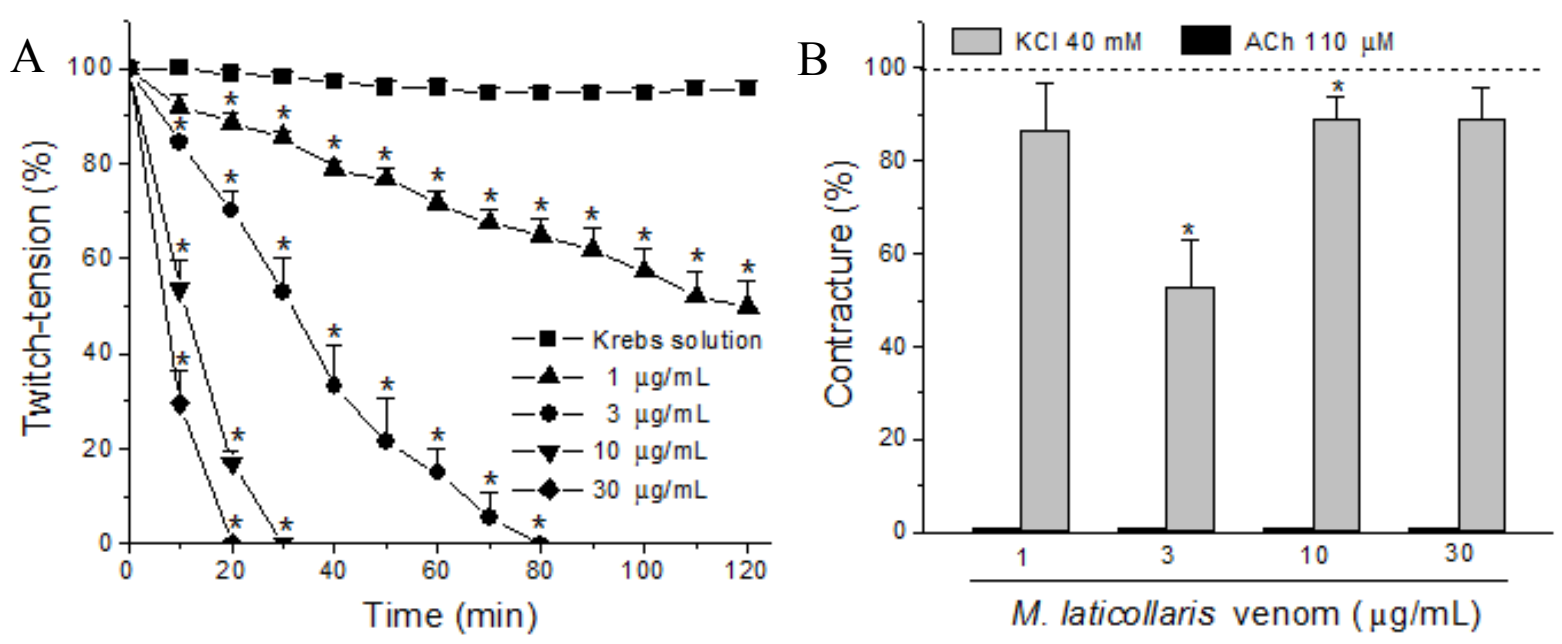

In mouse phrenic-nerve diaphragm (PND) preparations, the M. laticollaris venom (one, three and $10 \mu \mathrm{g} / \mathrm{mL}$ ) also produced irreversible time- and concentration-dependent blockade, although less active than that of biventer cervicis (BC) preparations, with complete neuromuscular blockade occurring just at the highest concentration $(10 \mu \mathrm{g} / \mathrm{mL}$; time for $50 \%$ blockade: $26 \pm 3 \mathrm{~min})$ after $80 \mathrm{~min}$ of incubation, whereas $39 \% \pm 11 \%$ and $88 \% \pm 1 \%$ blockade for one and $3 \mu \mathrm{g} / \mathrm{mL}$, respectively, were observed after $120 \mathrm{~min}$. (Figure 2). Figure 3B, the PND preparation, shows a representative record of the neuromuscular blockade caused by the venom $(10 \mu \mathrm{g} / \mathrm{mL})$ preceded by a marked increase in the baseline (contracture). The difference in sensitivity of the chick biventer cervicis and mouse diaphragm preparations to $M$. laticollaris venom is a fact. The explanation must rely not only the 
species selectivity of animal toxins [30,31], but also on the anatomical differences between mouse diaphragm (single innervated fiber, en plaque endings) and chick biventer end-plates (multiple innervated fiber, en grape endings) [32]. Furthermore, the existence of two populations of nicotinic receptors in $\mathrm{BC}$ preparations is well-known [33,34], i.e., one population that is extrajunctional and responds well to exogenous Ach, but is rapidly blocked by venom neurotoxins, and another located in the motor end-plate that responds to nerve stimulation and is less susceptible to rapid blockade by neurotoxins (possibly because of difficulties related to toxin diffusion into the synaptic cleft). This also agrees with studies for other neurotoxins that discriminate between these two populations [35,36] (Chang et al., 1973; Chang and Su, 1975). Chemical differences between junctional and extrajunctional receptors obviously could also be a clue to the molecular mechanisms involved in generating and maintaining these differences. Studies using chimeric subunits and site-direct mutagenesis have demonstrated the importance of amino acids located within loops $\mathrm{D}, \mathrm{E}$ and $\mathrm{F}$ in determining selectivity for nicotinic agonists and antagonists [37-40]. In addition, the differences in maturity of the nicotinic receptors present in both species must complement a reasonable explanation. To date, the neuromuscular $\mathrm{nAChR}$ is a pentamer comprised of two $\alpha 1$ subunits, one $\beta 1$ subunit, one $\delta$ subunit and either a $\gamma$ or an $\varepsilon$ subunit. In mammals, the $\gamma$ subunit (fetal subtype) is replaced by the $\varepsilon$ subunit (adult subtype) during development. In mice, the $\varepsilon$ subunit is known to replace the $\gamma$ subunit during the first 14 days postnatal [41]. Normally, both presynaptic and postsynaptic effects can be observed in murine nerve-muscle preparations assayed with Elapidic venoms [22,42]. The presence of $\mathrm{PLA}_{2}$-neurotoxins in these venoms induces a triphasic effect, i.e., the increase of the muscle twitch-tension amplitude before the irreversible neuromuscular blockade [21], as it was also observed in PND preparations treated with $3 \mu \mathrm{g}$ of $M$. laticollaris venom $/ \mathrm{mL}$ (see Figure 2). In addition, the initial neuromuscular facilitation caused by Micrurus venoms could be a result of an increase in neurotransmitter release [42] that can be partly due to a modulation of miniature end-plate potential (MEPP) parameters $[21,43]$.

Figure 2. Concentration- and time-dependent neuromuscular blockade caused by M. laticollaris venom (one, three and $10 \mu \mathrm{g} / \mathrm{mL}$ ) in phrenic-nerve diaphragm (PND) preparations. Note that a $3 \mu \mathrm{g} / \mathrm{mL}$ venom concentration caused a minor neuromuscular facilitation after $10 \mathrm{~min}$ of incubation. The points are the mean $\pm \operatorname{SEM}(n=4) ; * p<0.05$ compared to control preparations.

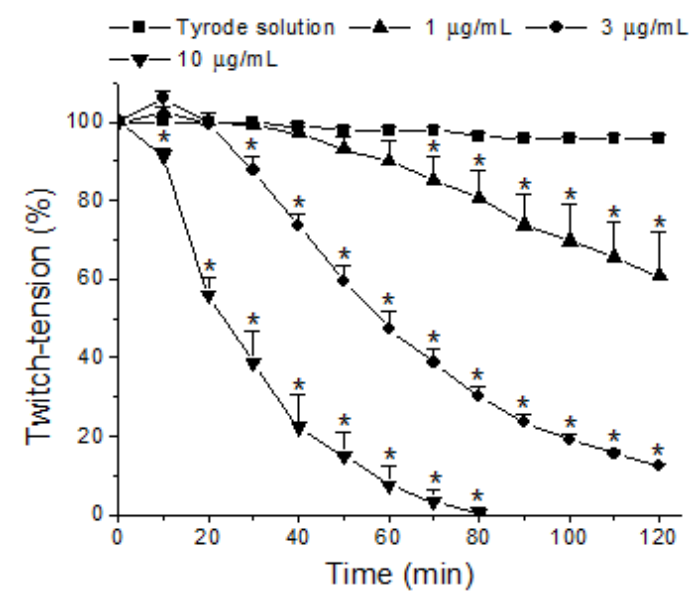


Figure 3. Neuromuscular blockade caused by $M$. laticollaris venom in BC and PND preparations. (A) Representative recordings showing the blockade caused by M. laticollaris venom $(10 \mu \mathrm{g} / \mathrm{mL})$ in a BC preparation indirectly stimulated at $37^{\circ} \mathrm{C}$. Note that responses to exogenous $\mathrm{ACh}(\boldsymbol{\Delta}, 110 \mu \mathrm{M})$ were completely abolished by venom, whereas those to $\mathrm{KCl}(\mathbf{\square}, 40 \mathrm{mM})$ had a minor decrease; (B) Representative recordings showing the blockade caused by $M$. laticollaris venom $(10 \mu \mathrm{g} / \mathrm{mL})$ in a PND preparation indirectly stimulated at $37^{\circ} \mathrm{C}$. This venom concentration caused contracture in the baseline from 20 min of incubation.
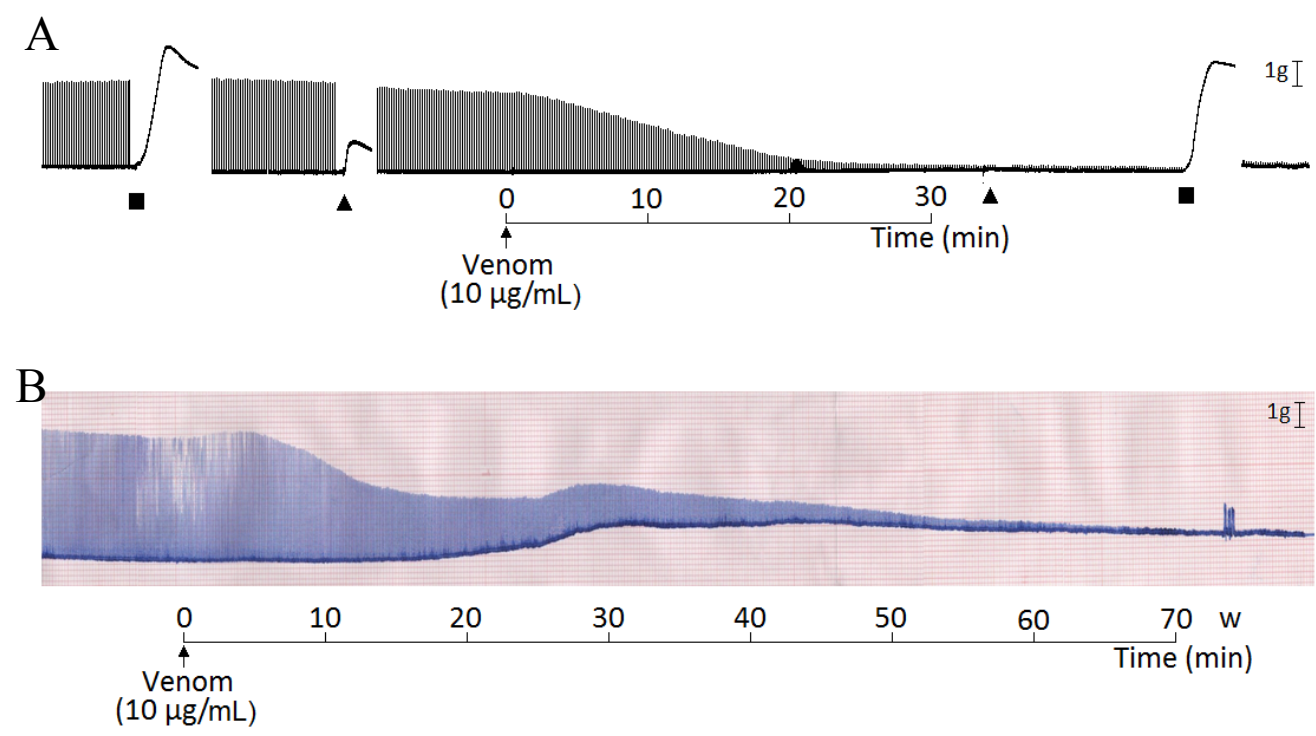

Figure 4. Miniature end-plate potential (MEPP) measurements in PND preparations treated with $M$. laticollaris venom. The columns are the mean \pm SEM of four muscles in which three different end-plates were measured per interval; $* p<0.05$ compared to $t_{0}$ (control) values.

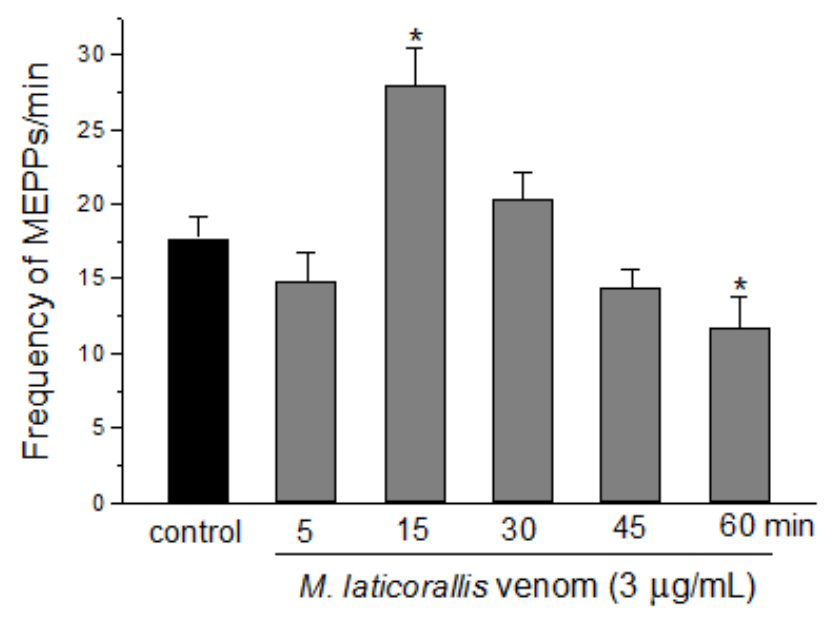

Indeed, M. laticollaris venom (3 $\mu \mathrm{g} / \mathrm{mL})$ induced a significant increase in the frequency of miniature end-plate potentials (MEPPs/min) in mouse diaphragm after $15 \mathrm{~min}$ and then a decrease after $60 \mathrm{~min}$ (from $17 \pm 1.4$ (basal) to $28 \pm 2.5\left(t_{15}\right)$ and $\left.12 \pm 2\left(t_{60}\right) ; n=4\right)$ (Figure 4), with no important alteration in the MEPPs' amplitude $(\mathrm{mV}: 1.2 \pm 0.02,1.4 \pm 0.02,1.3 \pm 0.02,1.2 \pm 0.02$, $1.1 \pm 0.02$ and $1.2 \pm 0.02$ for $t_{0}$ (basal), $t_{5}, t_{15}, t_{30}, t_{45}$ and $t_{60}$ min, respectively, $n=4$ ). As discussed 
above, this effect could contribute to an increase of neurotransmitter release before the onset of neuromuscular blockade. This conclusion also exposes the presence of presynaptic neurotoxins in M. laticollaris venom, which are probably related to $\mathrm{PLA}_{2}$-neurotoxin actions $[21,22,42,43]$.

Figure 5. Membrane resting potential measurements in curarized and uncurarized PND preparations treated with M. laticollaris venom. (A) The depolarizing effect caused by venom $(10 \mu \mathrm{g} / \mathrm{mL})$ in uncurarized preparations; (B) The lack of depolarization by d-tubocurarine (d-Tc, $5 \mu \mathrm{g} / \mathrm{mL}$ ) after $120 \mathrm{~min}$ of incubation; (C) The depolarizing effect caused by venom $(10 \mu \mathrm{g} / \mathrm{mL})$ in preparations previously treated with d-Tc $(5 \mu \mathrm{g} / \mathrm{mL})$ for $10 \mathrm{~min}$. Note that pretreatment with $\mathrm{d}-\mathrm{Tc}$ did not prevent the depolarizing effect caused by venom. The columns are the mean \pm SEM of four muscles in which six different end-plates were measured per interval; $* p<0.05$ compared to $t_{0}$ (control) values in all panels.

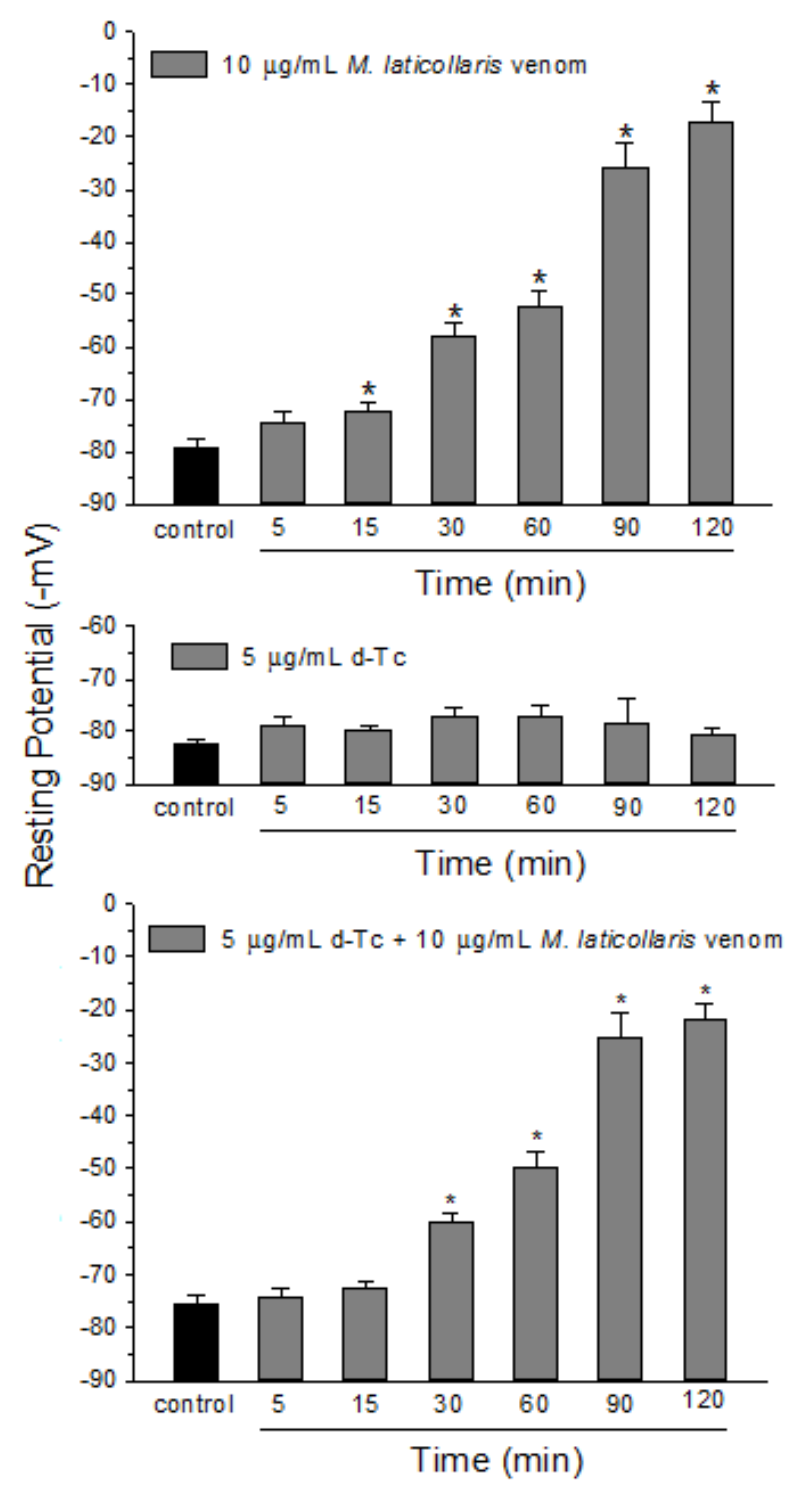

It was also observed that the venom $(10 \mu \mathrm{g} / \mathrm{mL})$ caused a significant membrane depolarization from 15 min of incubation in PND preparations (from $-79 \pm 1.6 \mathrm{mV}\left(t_{0}\right)$ to $-17 \pm 3.7 \mathrm{mV}\left(t_{120}\right) ; n=4$ ) (Figure 5, higher panel). Figure 5 (intermediate panel) is a positive control experiment that shows the 
lack of depolarization in preparations incubated with d-tubocurarine (d-Tc, $5 \mu \mathrm{g} / \mathrm{mL})$ for $120 \mathrm{~min}$ (from $-82 \pm 1 \mathrm{mV}\left(t_{0}\right)$ to $-81 \pm 1.3 \mathrm{mV}\left(t_{120}\right) ; n=4$ ). However, preparations pretreated with d-Tc $(5 \mu \mathrm{g} / \mathrm{mL})$ for $10 \mathrm{~min}$ and then exposed to venom $(10 \mu \mathrm{g} / \mathrm{mL})$ also exhibited important membrane depolarization from $30 \mathrm{~min}$ of venom incubation (from-75 $\pm 1.7 \mathrm{mV}\left(t_{0}\right)$ to $-22 \pm 3 \mathrm{mV}\left(t_{120}\right) ; n=4$ ) (Figure 5-lower panel). Myotoxicity is a common phenomenon related to the activity of Micrurus venoms in nerve-muscle preparations $[38,40,41]$. PLA $_{2}$-myotoxins present in Micrurus venoms are responsible for morphological alterations in skeletal muscle [21,38,42]. In addition, the activity of $\mathrm{PLA}_{2}$-myotoxins in nerve-muscle preparations normally induces a decrease in the resting membrane potential [21,43-46]. We suggest that the membrane depolarization caused by M. laticollaris as observed here, apart from alteration of the baseline and changes in the contracture to $\mathrm{KCl}$ in the twitch-tension experiments, can also be related to the presence of $\mathrm{PLA}_{2}$-myotoxins in the composition of this venom.

\section{Experimental Section}

\subsection{Venom and Animals}

Micrurus laticollaris venom (Mexican coral snake) was provided, in a lyophilized form, by Instituto de Biotecnología of the Universidad Nacional Autónoma de México (Cuernavaca, Morelos, Mexico). When required, the venom was dissolved in Krebs or Tyrode solution prior to use. Male Swiss mice $(25-30 \mathrm{~g})$ obtained from the Multidisciplinary Center for Biological Investigation (CEMIB/Unicamp) were housed 10 /cage at $23{ }^{\circ} \mathrm{C}$ on a $12 \mathrm{~h} \mathrm{light/dark} \mathrm{cycle} \mathrm{with} \mathrm{lights} \mathrm{on} \mathrm{at} 6$ a.m. Male HY-LINE chicks (4-8 days old) were supplied by Globo Aves Agricola Ltda. (Campinas, SP, Brazil) and were housed in metal cages with a sawdust substrate. The mice and chicks had free access to food and water.

\subsection{Twitch-Tension Experiments}

Chick biventer cervicis nerve-muscle preparations (BC) were mounted (resting tension: $1 \mathrm{~g}$ ) in Krebs solution (composition, in $\mathrm{mM}: \mathrm{NaCl} 119, \mathrm{KCl} 4.7, \mathrm{CaCl}_{2} 1.9, \mathrm{KH}_{2} \mathrm{PO}_{4} 1.2, \mathrm{MgSO}_{4} 1.2$, $\mathrm{NaHCO}_{3} 25$ and glucose $11.7, \mathrm{pH} 7.5$ at $37{ }^{\circ} \mathrm{C}$, after equilibration with $95 \% \mathrm{O}_{2} / 5 \% \mathrm{CO}_{2}$ ) and allowed to stabilize for $20 \mathrm{~min}$ prior to use, as described elsewhere $[47,48]$. Field stimulation $(0.1 \mathrm{~Hz}, 0.2 \mathrm{~ms})$ were delivered from an LE 12406 TC stimulator (Panlab, Spain), and the muscle twitches were recorded using a TRI201AD force displacement transducer coupled to a Quad Bridge Amp and LabChart 6.0 software (all from ADInstruments Pty Ltd., Bella Vista, Australia). Muscle responses to exogenous acetylcholine ( $\mathrm{ACh}, 110 \mu \mathrm{M})$ and $\mathrm{KCl}(40 \mathrm{mM})$ were obtained before and after incubation with venom (1-30 $\mu \mathrm{g} / \mathrm{mL})$ to screen for postsynaptic neurotoxicity and myotoxicity [49].

Mouse phrenic nerve-diaphragm preparations (PND) were mounted in Tyrode solution (composition, in mM: $\mathrm{NaCl} 137, \mathrm{KCl} 2.7, \mathrm{CaCl}_{2} 1.8, \mathrm{MgCl}_{2} 0.49, \mathrm{NaH}_{2} \mathrm{PO}_{4} 0.42, \mathrm{NaHCO}_{3} 11.9$ and glucose 11.1, pH 7.0 at $37{ }^{\circ} \mathrm{C}$, after equilibration with $\left.95 \% \mathrm{O}_{2} / 5 \% \mathrm{CO}_{2}\right)$, as described elsewhere [48,50]. Supramaximal stimuli $(0.1 \mathrm{~Hz}$ and $0.2 \mathrm{~ms})$ were delivered to the nerve from a Grass S88 stimulator (Grass Instrument Co., Quincy, MA, USA), and the muscle twitches were recorded using a Load Cell BG-25 g force displacement transducer coupled to a Gould RS 3400 recorder (both from Gould Inc., 
Cleveland, OH, USA). After stabilization for $20 \mathrm{~min}$, the preparations were incubated with different venom concentrations $(1,3$ and $10 \mu \mathrm{g} / \mathrm{mL})$ for $120 \mathrm{~min}$ or complete neuromuscular blockade and the changes in twitch-tension recorded.

\subsection{Intracellular Recordings}

The effect of the venom on the frequency of miniature end-plate potentials (MEPPs) and membrane resting potential (RP) was recorded using mouse hemidiaphragm muscle mounted in a Lucite chamber containing Tyrode solution (composition shown above), as described previously elsewhere $[24,48]$. The MEPPs frequency was measured in multiple neuromuscular junctions at various intervals from control $\left(t_{0}\right)$ and venom-treated preparations $\left(t_{5}-t_{60}\right)$. For RP measurements, different regions of the muscle were monitored at various intervals from control $\left(t_{0}\right)$ and venom-treated preparations $\left(t_{5}-t_{120}\right.$ for RP); some preparations were pre-incubated with d-tubocurarine (d-Tc, $5 \mu \mathrm{g} / \mathrm{mL}$ ), a non-depolarizing compound, to verify the venom activity on nicotinic receptors and/or the muscle membrane.

\subsection{Statistical Analysis}

Changes in the twitch-tension responses of BC and PND preparations and the membrane resting potential of PND preparations were expressed as a percentage relative to baseline (time zero) values. The results were expressed as the mean \pm SEM, and statistical comparisons were done using the Student's $t$-test or ANOVA, followed by the Tukey test, with $p<0.05$ indicating significance. All data analyses were done using Microcal Origin software (Microcal Software Inc., Northampton, MA, USA).

\section{Conclusions}

Based on these results, we conclude that Micrurus laticollaris venom causes neuromuscular blockade in avian and mammalian preparations in vitro essentially by a combined postsynaptic action between nicotinic receptor blockade and muscle membrane resting potential depolarization, since contracture responses to exogenous $\mathrm{ACh}$ in $\mathrm{BC}$ preparations was completely inhibited by all venom concentrations tested, and there was a significant depolarization of the muscle fiber membrane caused by venom in PND preparations. The venom-induced blockade was preceded by a presynaptic effect, which initially facilitates neurotransmitter release, as shown by the increase in twitch-tension amplitude and the frequency of MEPPs in PND preparations, suggesting also the presence of $\beta$-neurotoxins in the crude venom.

\section{Acknowledgments}

The authors thank Gildo B. Leite for technical assistance.

\section{Conflicts of Interest}

The authors declare no conflict of interest. 


\section{References}

1. Roze, J.A. New World coral snakes (Elapidae): A taxonomic and biological summary. Mem. Inst. Butantan 1982, 46, 305-338.

2. Roze, J.A. New species and subspecies of coral snakes, genus Micrurus (Elapidae), with notes on type specimens of several species. Am. Mus. Novitates 1989, 2932, 1-15.

3. Roze, J.A.; Bernal-Carlo, A. Las serpientes corales venenosas del genero Leptomicrurus (serpentes, Elapidae) de Suramérica con descripción de una nueva subespécie. Boll. Mus. Reg. Sci. Nat. Torino 1987, 5, 573-608.

4. Aird, S.D.; da Silva, N.J., Jr. Comparative enzymatic composition of Brazilian coral snake (Micrurus) venoms. Comp. Biochem. Physiol. B 1991, 99, 287-294.

5. Campbell, J.A.; Lamar, W.W. The Venomous Reptiles of Latin America; Comstock Publishers/Cornell University Press: Ithaca, NY, USA, 1989.

6. Roze, J.A. Coral Snakes of the Americas. Biology, Identification and Venoms; Struik Publishing Co.: Malabar, FL, USA, 1996.

7. Vital-Brazil, O. Coral snake venoms: Mode of action and pathophysiology of experimental envenomation. Rev. Inst. Med. Trop. Sao Paulo 1987, 29, 119-126.

8. Rosso, J.P.; Vargas-Rosso, O.; Gutiérrez, J.M.; Rochat, H.; Bougis, P.E. Characterization of alpha-neurotoxin and phospholipase $\mathrm{A}_{2}$ activities from Micrurus venoms. Determination of the amino acid sequence and receptor-binding ability of the major alpha-neurotoxin from Micrurus nigrocinctus nigrocinctus. Eur. J. Biochem. 1996, 238, 231-239.

9. Alape-Girón, A.; Stiles, B.; Schmidt, J.; Girón-Cortes, M.; Thelestam, M.; Jörnvall, H.; Bergman, T. Characterization of multiple nicotinic acetylcholine receptor-binding proteins and phospholipases $\mathrm{A}_{2}$ from the venom of the coral snake Micrurus nigrocinctus. FEBS J. 1996, 380, 29-32.

10. de Oliveira, J.S.; da Silva, A.R.B.; Soares, M.B.; Stephano, M.A.; Dias, W.O.; Raw, I.; Ho, P.L. Cloning and characterization of an a-neurotoxin- type protein specific for the coral snake Micrurus corallinus. Biochem. Biophys. Res. Comm. 2000, 267, 887-891.

11. Gutiérrez, J.M.; Lomonte, B.; Portilla, E.; Cerdas, L.; Rojas, E. Local effects induced by coral snake venoms: Evidence of myonecrosis after experimental inoculations of venoms from five species. Toxicon 1983, 21, 777-783.

12. Arroyo, O.; Rosso, J.P.; Vargas, O.; Gutiérrez, J.M.; Cerdas, L. Skeletal muscle necrosis induced by a phospholipase $\mathrm{A}_{2}$ isolated from the venom of the coral snake Micrurus nigrocinctus nigrocinctus. Comp. Biochem. Physiol. B 1987, 87, 949-952.

13. Goularte, F.C.; Cogo, J.C.; Gutiérrez, J.M.; Rodrigues-Simioni, L. The ability of specific antivenom and low temperature to inhibit the myotoxicity and neuromuscular block induced by Micrurus nigrocinctus venom. Toxicon 1995, 33, 679-689.

14. Alape-Girón, A.; Persson, B.; Cederlund, E.; Flores-Díaz, M.; Gutiérrez, J.M.; Thelestam, M.; Bergman, T.; Jörnvall, H. Elapid venom toxins: multiple recruitments of ancient scaffolds. Eur. J. Biochem. 1999, 259, 225-234.

15. Francis, B.R.; da Silva Júnior, N.J.; Seebart, C.; Casais e Silva, L.L.; Schmidt, J.J.; Kaiser, I.I. Toxins isolated from the venom of the Brazilian coral snake (Micrurus frontalis frontalis) include hemorrhagic type phospholipases $A_{2}$ and postsynaptic neurotoxins. Toxicon 1997, 35, 1193-1203. 
16. Tambourgi, D.V.; dos Santos, M.C.; de Furtado, M.F.; de Freitas, M.C.; da Silva, W.D.; Kipnis, T.L. Pro-inflammatory activities in elapid snake venoms. Br. J. Pharmacol. 1994, 112, 723-727.

17. Vital-Brazil, O.; Fontana, M.D. Ações pré-juncionais e pós-juncionais da peçonha da cobra coral Micrurus corallinus na junção neuromuscular. Mem. Inst. Butantan 1983/1984, 47/48, 13-26.

18. Cruz-Höfling, M.A.; Rodrigues-Simioni, L.; Vital-Brazil, O. Ultrastructural changes in neuromuscular junctions of mouse diaphragm caused by the venom of the coral snake Micrurus corallinus. Mem. Inst. Butantan 1983/1984, 47/48, 95-105.

19. Bolaños, R.; Cerdas, L.; Abalos, J.W. Venoms of coral snakes (Micrurus spp.): Report on a multivalent antivenin for the Americas. Bull. Pan Am. Health Organ. 1978, 12, 23-27.

20. Carbajal-Saucedo, A.; López-Vera, E.; Bénard-Valle, M.; Smith, E.N.; Zamudio, F.; de Roodt, A.R.; Olvera-Rodríguez, A. Isolation, characterization, cloning and expression of an alpha-neurotoxin from the venom of the Mexican coral snake Micrurus laticollaris (Squamata: Elapidae). Toxicon 2013, 66, 64-74.

21. Dal Belo, C.A.; Leite, G.B.; Toyama, M.H.; Marangoni, S.; Corrado, A.P.; Fontana, M.D.; Southan, A.; Rowan, E.G.; Hyslop, S.; Rodrigues-Simioni, L. Pharmacological and structural characterization of a novel phospholipase $\mathrm{A}_{2}$ from Micrurus dumerilii carinicauda venom. Toxicon 2005, 46, 736-750.

22. De Abreu, V.A.; Leite, G.B.; Borja-Oliveira, C.; Hyslop, S.; Furtado, M.F.D.; Rodrigues-Simioni, L. Neurotoxicity of Micrurus altirostris (Uruguayan coral snake) venom and its neutralization by commercial coral snake antivenom and specific antiserum raised in rabbits. Clin. Toxicol. 2008, 46, 519-527.

23. Camargo, T.M.; Roodt, A.R.; Cruz-Höfling, M.A.; Rodrigues-Simioni, L. The neuromuscular activity of Micrurus pyrrhocryptus venom and its neutralization by commercial and specific coral snake antivenoms. J. Venom Res. 2011, 2, 24-31.

24. Rey-Suárez, P.; Floriano, R.S.; Rostelato-Ferreira, S.; Saldarriaga-Córdoba, M.; Núñez, V.; Rodrigues-Simioni, L.; Lomonte, B. Mipartoxin-I, a novel three-finger toxin, is the major neurotoxic component in the venom of the redtail coral snake Micrurus mipartitus (Elapide). Toxicon 2012, 60, 851-863.

25. Kornhauser, R.; Isbister, G.K.; O’Leary, M.A.; Mirtschin, P.; Dunstan, N.; Hodgson, W.C. Cross-neutralization of the neurotoxic effects of Egyptian cobra venom with commercial tiger snake antivenom. Basic Clin. Pharmacol. Toxicol. 2013, 112, 138-143.

26. Ginsborg, B.L.; Warriner, J. The isolated chick biventer cervicis nerve muscle preparation. Br. J. Pharmacol. Chemother. 1960, 15, 410-411.

27. Clarke, C.; Kuruppu, S.; Reeve, S.; Ian Smith, A.; Hodgson, W.C. Oxylepitoxin-1, a reversible neurotoxin from the venom of the inland taipan (Oxyuranus microlepidotus). Peptides 2006, 27, 2655-2660.

28. Blacklow, B.; Kornhauser, R.; Hains, P.G.; Loiacono, R.; Escoubas, P.; Graudins, A.; Nicholson, G.M. $\alpha$-Elapitoxin-Aa2a, a long-chain snake $\alpha$-neurotoxin with potent actions on muscle $(\alpha 1)(2) \beta \gamma \delta$ nicotinic receptors, lacks the classical high affinity for neuronal $\alpha 7$ nicotinic receptors. Biochem. Pharmacol. 2011, 81, 314-325. 
29. Kornhauser, R.; Hart, A.J.; Reeve, S.; Smith, A.I.; Fry, B.G.; Hodgson, W.C. Variations in the pharmacological profile of post-synaptic neurotoxins isolated from the venoms of the Papuan (Oxyuranus scutellatus canni) and coastal (Oxyuranus scutellatus scutellatus) taipans. Neurotoxicology 2010, 31, 239-243.

30. Wickramaratna, J.C.; Hodgson, W.C. A pharmacological examination of venoms from three species of death adder (Acanthophis antarcticus, Acanthophis praelongus and Acanthophis pyrrhus). Toxicon 2001, 39, 209-216.

31. Young, G.T.; Broad, L.M.; Zwart, R.; Astles, P.C.; Bodkin, M.; Sher, E.; Millar, N.S. Species selectivity of a nicotinic acetylcholine receptor agonist is conferred by two adjacent extracellular $\beta 4$ amino acids that are implicated in the coupling of binding to channel gating. Mol. Pharmacol. 2007, 71, 389-397.

32. Toutant, J.P.; Rouaud, T.; le Douarin, G.H. Histochemical properties of the biventer cervicis muscle of the chick: A relationship between multiple innervation and slow-tonic fibre types. Histochem. J. 1981, 13, 481-493.

33. Chang, C.C.; Su, M.J.; Tung, L.H. Appearance of new acetylcholine receptors on the baby chick biventer cervicis and denervated rat diaphragm muscles after blockade with $\alpha$-bungarotoxin. J. Physiol. 1977, 268, 449-465.

34. Hodgson, W.C.; Wickramaratna, J.C. In vitro neuromuscular activity of snake venoms. Clin. Exp. Pharmacol. Physiol. 2002, 29, 807-814.

35. Chang, C.C.; Chen, T.F.; Chuang, S.T. N,O-di and N,N,O-tri $\left[{ }^{3} \mathrm{H}\right]$ acetyl $\alpha$-bungarotoxins as specific labeling agents of cholinergic receptors. Br. J. Pharmacol. 1973, 47, 147-160.

36. Chang, C.C.; Su, M.J. Further evidence that extrinsic acetylcholine acts preferentially on extrajunctional receptors in the chick biventer cervicis muscles. Eur. J. Pharmacol. 1975, 33, 337-344.

37. Figl, A.; Cohen, B.N.; Quick, M.W.; Davidson, N.; Lester, H.A. Regions of beta 4.beta 2 subunit chimeras that contribute to the agonist selectivity of neuronal nicotinic receptors. FEBS Lett. 1992 , 308, 245-248.

38. Czajkowski, C.; Kaufmann, C.; Karlin, A. Negatively charged amino acid residues in the nicotinic receptor delta subunit that contribute to the binding of acetylcholine. Proc. Natl. Acad. Sci. USA 1993, 90, 6285-6289.

39. Prince, R.J.; Sine, S.M. Molecular dissection of subunit interfaces in the acetylcholine receptor. Identification of residues that determine agonist selectivity. J. Biol. Chem. 1996, 271, 25770-25777.

40. Bren, N.; Sine, S.M. Identification of residues in the adult nicotinic acetylcholine receptor that confer selectivity for curariform antagonists. J. Biol. Chem. 1997, 272, 30793-30798.

41. Teichert, R.W.; Garcia, C.C.; Potian, J.G.; Schmidt, J.J.; Witzemann, V.; Olivera, B.M.; McArdle, J.J. Peptide-toxin tools for probing the expression and function of fetal and adult subtypes of the nicotinic acetylcholine receptor. Ann. N. Y. Acad. Sci. 2008, 1132, 61-70.

42. Serafim, F.G.; Reali, M.; da Cruz-Höfling, M.A.; Fontana, M.D. Action of Micrurus dumerilii carinicauda coral snake venom on the mammalian neuromuscular junction. Toxicon 2002, 40, 167-174. 
43. Goularte, F.C.; da Cruz-Höfling, M.A.; Corrado, A.P.; Rodrigues-Simioni, L. Electrophysiological and ultrastructural analysis of the neuromuscular blockade and miotoxicity induced by the Micrurus nigrocinctus snake venom. Acta Physiol. Pharmacol. Ther. Latinoam. 1999, 49, 290-296.

44. Barros, A.C.; Fernandes, D.P.; Ferreira, L.C.; Dos Santos, M.C. Local effects induced by venoms from five species of genus Micrurus sp. (coral snakes). Toxicon 1994, 32, 445-452.

45. de Roodt, A.R.; Lago, N.R.; Stock, R.P. Myotoxicity and nephrotoxicity by Micrurus venoms in experimental envenomation. Toxicon 2012, 59, 356-364.

46. Fernández, J.; Alape-Girón, A.; Angulo, Y.; Sanz, L.; Gutiérrez, J.M.; Calvete, J.J.; Lomonte, B. Venomic and antivenomic analyses of the Central American coral snake, Micrurus nigrocinctus (Elapidae). J. Proteome Res. 2011, 10, 1816-1827.

47. Rodrigues-Simioni, L.; Floriano, R.S.; Rostelato-Ferreira, S.; Sousa, N.C.; Marangoni, S.; Ponce-Soto, L.A.; Carregari, V.C.; Hyslop, S. Presynaptic action of Bothriopsis bilineata smargadina (forest viper) venom in vitro. Toxicon 2011, 58, 140-145.

48. Floriano, R.S.; Carregari, V.C.; de Abreu, V.A.; Kenzo-Kagawa, B.; Ponce-Soto, L.A.; da Cruz-Höfling, M.A.; Hyslop, H.; Marangoni, S.; Rodrigues-Simioni, L. Pharmacological study of a new Asp49 phospholipase $\mathrm{A}_{2}$ (Bbil-TX) isolated from Bothriopsis bilineata smargadina (forest viper) venom in vertebrate neuromuscular preparations. Toxicon 2013, 69, 191-199.

49. Harvey, A.L.; Barfarz, A.; Thompson, E.; Faiz, A.; Preston, S.; Harris, J.B. Screening of snake venoms for neurotoxic and myotoxic effects using simple in vitro preparations from rodents and chicks. Toxicon 1994, 32, 257-265.

50. Oshima-Franco, Y.; Leite, G.B.; dal Belo, C.A.; Hyslop, S.; Prado-Franceschi, J.; Cintra, A.C.; Giglio, J.R.; da Cruz-Höfling, M.A.; Rodrigues-Simioni, L. The presynaptic activity of bothropstoxin-I, a myotoxin from Bothrops jararacussu snake venom. Basic Clin. Pharmacol. Toxicol. 2004, 95, 175-182.

(C) 2014 by the authors; licensee MDPI, Basel, Switzerland. This article is an open access article distributed under the terms and conditions of the Creative Commons Attribution license (http://creativecommons.org/licenses/by/3.0/). 